\title{
Going the Distance: Online Course Performance and Motivation of Distance Learning Students
}

\author{
Tiffaney D. Hobson and Krista K. Puruhito \\ Arizona State University
}

\begin{abstract}
This study was designed to better understand what drives the learning and performance of students enrolled in distance-learning courses. Between 1999 and 2015, the number of students enrolled in at least one online course increased from $10 \%$ to $30 \%$ (NCES, 2014; NCES, 2018). Of the six million students currently enrolled in at least one distance-learning course, close to half are enrolled in programs that are offered exclusively online (Allen \& Seaman, 2017; NCES, 2018). This enrollment growth, however, is coupled with an alarming attrition rate as high as $80 \%$ (Smith, 2010). As GPA and course performance have been linked to distance-learning persistence and retention, we found it imperative to explore differences in motivational orientations as they relate to passing and failing status for an individual course. To do so, we surveyed distance-learning students and identified correlations between motivational constructs such as instrumentality, selfefficacy, connectedness, use of knowledge-building strategies, and final course performance. Differences related to gender and major/non-major status are also reviewed and discussed. These findings offer insights into next steps for research and also inform teaching practice.
\end{abstract}

Keywords: motivation of online learners, instrumentality, knowledge building, connectedness

Hobson, T.D., \& Puruhito, K.K. (2018). Going the distance: Online course performance and motivation of distance-learning students. Online Learning, 22(4), 129-140. doi:10.24059/olj.v22i4.1516

\section{Going the Distance: Online Course Performance and Motivation of Distance-Learning Students}

Enrollment data published by the National Center for Education Statistics (2014) show that $25.8 \%$ of students (5.45 million) attending Title IV institutions are enrolled in at least one distance-learning course. Post-secondary education is growing more diverse as online coursework affords greater flexibility in obtaining undergraduate and graduate degrees. Many institutions now offer degree programs that can be completed entirely online. The Distance Education Enrollment Report compiled by BABSON Survey Research Group (Allen \& Seaman, 2017) highlights that, between 2012 and 2015, the number of students enrolled in distance-learning degree programs increased from $12.6 \%$ to $14.3 \%$. During this time, a total of 2,902,756 individuals were enrolled in programs completed exclusively online. This enrollment growth demonstrates that distance 
learning continues to be a desired platform. High attrition rates, however, are alarming to both educators and the institutions providing these programs.

While campus-based programs in the US and UK have graduation rates around $80 \%$, distance-learning programs have rates close to 20\% (Simpson, 2013). Smith (2010) notes that attrition rates among distance learners fluctuates between 40-80\%. Identifying reasons for such low retention has been the focus of numerous studies. One particular study on student retention conducted by Craig and Ward (2008) found that individuals who dropped out of community college coursework prior to transferring and/or graduating had significantly lower grades than students who persisted. Willging and Johnson (2009) identified academic difficulty as a programrelated influence on distance-learning student dropout rates. With degree attainment a goal, exploring how motivational constructs vary among passing and failing students is prudent.

Researchers have considered numerous factors that influence student attrition. Rovai (2003) developed a retention model that considers how internal factors, such as motivation, selfdiscipline, and GPA impact retention. When online courses do not match the pedagogy expected by students and/or when instructors are unable to adapt to meet the needs of distance learners, greater dissatisfaction occurs (Rovai, 2003).

Research conducted by Spahr (2015) compared learning method (distancelearning/campus-based), gender, and internal factors such as motivation of graduate students. Male students reported more extrinsic motivation than their female peers. Shell and Soh (2013) also found differences in motivation and performance of campus-based students when enrolled in major versus non-major related courses. Students majoring in family science will, presumably, have greater vested interest in learning the content presented within family science courses. Based on this previous research with campus-based students, we expect that the differences between major and non-major distance-learning students will also be significant, specifically with regard to future time perspective and knowledge-building orientations.

Yoo and Huang (2013) identified gender as a factor influencing distance-learning motivation differences. Their study sought to broadly explore whether differences existed between male and female students with regards to intrinsic and extrinsic motivation. Females were found to have significantly greater intrinsic motivation while differences in extrinsic motivation were not notable. We seek to expand on these findings to explore how gender influences motivation even when academic performance is comparable between male and female students.

It is documented in the literature that, for campus-based students, motivation can impact the ability to utilize optimal knowledge-building skills and engage in course content, both of which allow for learning to occur and for the students to experience success and perform well in the class (Shell, Husman, Turner, Cliffel, Nath, \& Sweany, 2005). We know far less about how these contribute to the success of online students, and it is essential that researchers understand this population if we aim to improve student retention. In doing so, instructors can adapt to meet the educational needs of students with various types of motivational orientations.

\section{Theoretical Background}

The work in this paper pulls primarily from two bodies of research. The first is future time perspective theories. Future time perspective (FTP) theories explain how perceptions and anticipations of future goals affect individuals' motivation for the task at hand (Husman \& Lens, 1999; Lang \& Carstensen, 2002; Malka \& Covington, 2005; Zimbardo \& Boyd, 1999). FTP is 
inherently future oriented because we cannot have goals for the past. FTP is a person's global view of their imagined future and can be measured in four dimensions: speed, distance, valence, and connectedness (Husman and Lens, 1999). Connectedness, the dimension we focus on in this study, is defined as the capacity of an individual to make connections between tasks at hand and the person's imagined future (Bembenutty, 2009; Bong, 2001; Husman, Derryberry, Crowson, \& Lomax, 2004; Simons, Dewitte, \& Lens, 2004). Connectedness has been shown in previous studies to be a good predictor of student achievement in college classrooms (Shell \& Husman, 2001).

The second body of research that this study pulls from is expectancy-value theory. Expectancy-value theory of motivation states that an individual's choice, persistence, and performance can be explained by their belief about how well they do on the activity (expectancy) and the extent to which they value that activity (value) (Wigfield \& Eccles, 2000). In the context of education, this means that how well an individual performs on an academic task depends on how high their expectations are about success (self-efficacy) and the value placed on being successful at that task (instrumentality).

The first component of the expectancy-value model is how well one expects to do on a task. This is called self-efficacy (Bandura, 1997, Zimmerman \& Bandura, 1994). Self-efficacy is important because persistence at an activity can be determined in part by how well we think we can accomplish it (Multon, Brown, \& Lent, 1991). If we have low self-efficacy for a task, we are not likely to continue to engage in it. In the context of this study, we ask students how well they think they can do in the class. This is very similar to outcome expectancy as defined and used by Zimmerman \& Bandura (2004) and expectancy for success as defined by Shell and Husman (2008). High reports of self-efficacy are linked to self-reports of optimal use of knowledgebuilding skills and higher academic achievement (Puruhito, 2017; Shell \& Husman, 2008; Zimmerman \& Bandura, 1994).

The second component of the expectancy-value model is value, or what we further define as instrumentality. Instrumentality is the usefulness of something for a future goal. Research on this construct also pulls from FTP theories as it is inherently future oriented. Research has identified three distinct types of instrumentality: endogenous, exogenous, and extrinsic. Endogenous instrumentality is the perception that learning or mastering new information or concepts is useful to achieving long-term future goals (Husman, Derryberry, Crowson, \& Lomax, 2004). This type of instrumentality focuses on learning and mastering the task at hand, with an understanding that the task itself is important. In contrast, exogenous instrumentality is the perception that the completion of a task or attainment of an external reward is instrumental to achieving a future goal (Husman, et al., 2004). Both of these types of instrumentality may enhance motivation and can occur together. It is the third type of instrumentality-extrinsic instrumentality - that undermines motivation and is externally regulated. Extrinsic instrumentality is dichotomous to endogenous instrumentality. It is the value only of the outcome itself with no value for the task (ie, getting an A on a final paper, without caring about what is learned). Puruhito (2017) demonstrated that students who endorse extrinsic instrumentality for grade report decreased use of knowledge-building strategies.

The future time orientation of instrumentality is of specific importance for many reasons. Research has shown that a student's ability to link academic tasks to future goals is important (Miller, DeBacker, \& Greene, 1999) and that endogenous and exogenous instrumentality increases intrinsic motivation (Husman, et al., 2004; Lens, 2002). This study is the first to explore the impact of extrinsic instrumentality on final course grades. It has also been found that students who self- 
report higher levels of connectedness and intrinsic instrumentality also report higher use of optimal knowledge-building skills, which is linked to academic success (Bong, 2001, Shell, et al., 2005).

Using an approach that combines both expectancy-value theory (Wigfield \& Eccles, 1992) as well as future time perspective (Husman \& Lens, 1999), we approach the research questions with a future orientation. In addition to learning more about what online student motivation looks like, we also seek to understand the relationship between major/non-major status and gender on learning and instrumentality in an online course. Our research questions are as follows:

RQ1: In which ways, if any, do connectedness, self-efficacy, knowledge building, instrumentality, and course performance differ among male and female distance learning students?

RQ2a: Do distance learning students differ in connectedness, self-efficacy, knowledge building, instrumentality, and performance when enrolled in major-related versus nonmajor related courses?

RQ2b: Did students majoring in family studies differ in final course grade from those who were not family studies majors?

\section{Methods}

Students were solicited for participation by the researcher via an announcement that was posted in the online courses and were offered extra credit for completing the survey. During week 4 of a 7-week session, 409 of the 570 college students enrolled in online family science courses in 2017 at a large university in the Southwestern United States volunteered to participate. Of these, 338 identified as female, 69 identified as male, and 2 preferred to not identify. While 125 students reported family studies as their major, the other 284 students reported majors in other fields. Using final letter grade as a measure of performance/learning, we sought to evaluate relationships between connectedness, self-efficacy, knowledge building, endogenous, exogenous, extrinsic instrumentality, and major status of students in an online course. At the end of the survey, gender and major information were also collected. Final course grades were obtained from the instructor at the end of the session. Consent was provided by all participants for researchers to obtain their final course grade from the instructor.

The Future Time Perspective Scale (FTPS) developed by Husman and Shell (2008) is included as a measure of global future-oriented thinking. The Connectedness subscale is the only part of this measure that was used in this study (6 items; e.g., "Planning for what I will do after college graduation is a good use of time."). Cronbach alphas of .74 to .81 for the Connectedness subscale have been reported (Hilpert et al., 2012; Puruhito, 2017). All items used a 5 point Likert response scale with a sixth option ("I prefer not to answer").

Self-efficacy has been used as a measure of expectancy (expectancy-value theory) and was measured in this study using a self-efficacy for grade item developed by Shell, Murphy \& Bruning (1989). This item asked students to indicate the highest grade that they felt able to achieve in the course. Here, this item measured their self-efficacy for doing well in the course, or academic achievement, which is one of the constructs of interest. Response options ranged from A (6) to D+ (1). Participants also had the option of selecting "No Comment" (0). 
The Knowledge Building Subscale (KB) from the Student Perceptions of Classroom Knowledge Building (SPOCK) consists of 8 items (e.g., "As I study topics in other classes, I try to think about how they relate to the topics I am studying in (insert course name\}") and is used to measure students' perceived use of self-regulated learning strategies (Shell, et al., 2005). Coefficient alphas of $.83 \& .84$ were reported during scale development. Responses were recorded on a Likert-type scale ranging from 1 (strongly disagree) to 5 (strongly agree) with an additional option of "I prefer not to answer."

The Perceptions of Instrumentality Scale (Husman, et. al, 2004) consists of two subscales with 4 items each, the Endogenous (EndoPI) subscale and the exogenous (ExoPI) subscale. This scale is intended to measure a task's importance as it relates to the achievement of a future goal. The endogenous instrumentality subscale consisted of four items (e.g., "What I gain from \{insert course name \} will shape my future") and the exogenous instrumentality subscale consisted of four items (e.g., "I must pass this class in order to reach my academic goals"). Alpha coefficients for the original scale were reported at .90 for endogenous and .64 for exogenous (Hilpert et al., 2012). Responses were recorded on a Likert-type scale ranging from 1 (strongly disagree) to 5 (strongly agree) with an additional option of "I prefer not to answer."

The Extrinsic Instrumentality subscale was developed and validated in 2017 as an extension of the Perceptions of instrumentality Scale (Puruhito, 2017). This scale is intended to measure a task's importance only as it relates to its usefulness for the achievement of another goal. This scale has four items (e.g., "The only aspect of this class that will matter after graduation is my grade"). Alpha coefficients for this scale were reported at .87 and .91 when the scale was validated (Puruhito, 2017). Responses were recorded on a Likert-type scale ranging from 1 (strongly disagree) to 5 (strongly agree) with an additional option of "I prefer not to answer."

\section{Data Analysis}

Descriptive statistics were computed and are provided in Table 1. Correlations were computed and are provided in Table 2. Two separate MANOVAs were conducted to explore the impact of gender and major status on FTP connectedness, self-efficacy, knowledge building, and the three types of instrumentality. Lastly, two ANOVAs were conducted to explore the impact of major status on course outcome (pass/fail) and the relationship between final course grade and extrinsic instrumentality.

Table 1

Descriptive Statistics

\begin{tabular}{lccccc}
\hline & & & & & $\begin{array}{c}\text { Std. } \\
\text { Deviation }\end{array}$ \\
\hline Exogenous Instrumentality & 409 & 1.00 & 5.00 & 3.74 & .73 \\
Endogenous Instrumentality & 409 & 1.00 & 5.00 & 4.13 & .65 \\
Extrinsic Instrumentality & 409 & 1.00 & 5.00 & 2.13 & .87 \\
FTP Connectedness & 409 & 1.17 & 5.00 & 3.78 & .72 \\
Knowledge Building & 409 & 1.00 & 5.00 & 4.04 & .58 \\
Self-Efficacy & 409 & 1.25 & 5.00 & 4.07 & .56 \\
& & & & & \\
\hline
\end{tabular}


Table 2

Correlations Between Study Variables

\begin{tabular}{|c|c|c|c|c|c|c|c|c|}
\hline & \multicolumn{7}{|c|}{ FTPS } & \multirow{2}{*}{$\begin{array}{c}\text { Final Letter } \\
\text { Grade }\end{array}$} \\
\hline & EndoPI & ExoPI & ExtPI & $\mathrm{CS}$ & KB & SE & Gender & \\
\hline EndoPI & 1 & & & & & & & \\
\hline ExoPI & $.17^{* *}$ & 1 & & & & & & \\
\hline ExtPI & $-.59^{* *}$ & -.08 & 1 & & & & & \\
\hline FTPSCS & $.70^{* *}$ & $.22^{* *}$ & $-.50^{* *}$ & 1 & & & & \\
\hline $\mathrm{KB}$ & $.69^{* *}$ & $24^{* *}$ & $-.50^{* *}$ & $.69^{* *}$ & 1 & & & \\
\hline SE & $.33^{* *}$ & .02 & $-.25^{* *}$ & $.33^{* *}$ & $.45^{* *}$ & 1 & & \\
\hline Gender & $.18^{* *}$ & .05 & $-.22^{* *}$ & $.19^{* *}$ & $.12^{*}$ & -.02 & 1 & \\
\hline Final letter grade & $.13^{*}$ & -.02 & $-.15^{* *}$ & .09 & $.17^{* *}$ & $.31^{* *}$ & -.05 & 1 \\
\hline Total points & $.13^{* *}$ & -.00 & $-.20^{* *}$ & .08 & $.17^{* *}$ & $.26^{* *}$ & -.066 & $.94^{* *}$ \\
\hline
\end{tabular}

\section{Results}

Final grade was found to be positively correlated with knowledge building (KB), $\mathrm{r}(407)=.17, p<.001$, and self-efficacy $(\mathrm{SE}), \mathrm{r}(407)=.31, p<.001$. While these scales were the only two identified that correlate directly with grade, it was found that they correlate significantly with the other constructs used in study. Knowledge building positively correlates with endogenous instrumentality, $\mathrm{r}(407)=.69, \quad p<.001$, exogenous instrumentality, $\mathrm{r}(407)=.24, \quad p<.001$, connectedness, $\mathrm{r}(407)=.69, p<.001$, and self-efficacy $\mathrm{r}(407)=.45, p<.001$. Additionally, selfefficacy was found to correlate positively with endogenous instrumentality, $\mathrm{r}(407)=.33, p<.001$ and connectedness, $\mathrm{r}(407)=.33, p<.000$. This may indicate that there is some mediation among the variables in this study. While the exogenous scale (ExoPI) does not correlate with self-efficacy, it was found in this study to positively correlate with endogenous instrumentality, $\mathrm{r}(407)=.17$, $p<.001$, connectedness, $\mathrm{r}(407)=.22, p<.001$, and knowledge building, $\mathrm{r}(407)=.24, p<.001$. Extrinsic instrumentality (ExtPI) was negatively correlated with all other study variables. Most important to note were endogenous instrumentality, $\mathrm{r}(407)=-.59 p<.001$, connectedness, $\mathrm{r}(407)=-$ $.50, p<.001$, knowledge building, $\mathrm{r}(407)=-.50, p<.001$, and self-efficacy, $\mathrm{r}(407)=-.25, p<.001$.

\section{RQ1 - Gender}

Results of a MANOVA (provided in Table 3) indicate that there was a statistically significant difference in reporting on motivational variables related to gender, $F(6,400)=4.681$, $\mathrm{p}<.01$; Wilk's $\Lambda=0.93$. Significant interactions were also identified for endogenous instrumentality, $\mathrm{F}(6,400)=12.92, \mathrm{p}<.001$, connectedness, $\mathrm{F}(6,400)=13.64, \mathrm{p}<.001$, extrinsic instrumentality, $F(6,400)=20.16, p<.001$, and knowledge building, $F(6,400)=4.79, p=.029$. There was no significant interaction effect between gender and self-efficacy, $F(6,400)=.073, p=.79$ or between gender and exogenous instrumentality, $\mathrm{F}(6,400)=.873, \mathrm{p}=.35$. Students who preferred to not disclose gender $(\mathrm{n}=2)$ were excluded from this analysis. 
Table 3

One-way MANOVA Between Subjects Effects for Gender as Independent Variable.

\begin{tabular}{lcccc}
\hline Dependent Variable & df & Mean Square & F & Sig. \\
\hline Exogenous Instrumentality & 1 & .47 & .873 & .35 \\
Endogenous Instrumentality & 1 & 5.39 & 12.92 & .00 \\
FTP Connectedness & 1 & 6.85 & 13.64 & .00 \\
Extrinsic Instrumentality & 1 & 14.73 & 20.16 & .01 \\
Knowledge Building & 1 & 1.57 & 4.79 & .03 \\
Self-efficacy & 1 & .02 & .07 & .79 \\
& & & & \\
\hline
\end{tabular}

\section{RQ2a - Major Status}

To aid in our understanding of differences between major and non-major students taking the courses in this study, a one-way multivariate analysis of variance was conducted, and results are provided in Table 4. Results (provided in Table 3) indicate that there was a statistically significant difference in reporting on motivational variables related to major status, $F(6,402)=$ 29.93, $\mathrm{p}=.00$; Wilk's $\Lambda=0.69$. It was discovered that majors reported significantly higher endogenous, $\mathrm{F}(1,407)=19.81, \mathrm{p}=.00$, exogenous $\mathrm{F},(1,407)=12.96, \quad p=.00$, connectedness, $\mathrm{F}(1,407)=131.99, p=.00$, and knowledge building, $\mathrm{F}(1,407)=17.62, \mathrm{p}=.00$ orientations. Selfefficacy was also higher among majors when compared to non-major peers, $\mathrm{F}(1,407)=6.38$, $p=.012$. Non-major students, however, were identified as having significantly higher extrinsic instrumentality, $\mathrm{F}(1,407)=22.11, p=.00$.

Table 4

One-way MANOVA Interactions for Major Status as Independent Variable

\begin{tabular}{lcccc}
\hline Dependent Variable & df & Mean Square & F & \multicolumn{1}{c}{ Sig. } \\
\hline Exogenous Instrumentality & 1 & 6.77 & 12.96 & .00 \\
Endogenous Instrumentality & 1 & 8.12 & 19.81 & .00 \\
FTP Connectedness & 1 & 51.74 & 131.99 & .00 \\
Extrinsic Instrumentality & 1 & 16.07 & 22.11 & .00 \\
Knowledge Building & 1 & 5.62 & 17.62 & .00 \\
Self-efficacy & 1 & 1.98 & 6.38 & .01 \\
\hline
\end{tabular}




\section{RQ2b - Final Course Grade}

An ANOVA was run to evaluate the effect of major status on students' final course grade. Results indicate that there is not a significant relationship between major/non major status and final course grade, $\mathrm{F}(1,407)=.15, \mathrm{p}=.70$. A second ANOVA was executed to evaluate the relationship between final course grade and extrinsic instrumentality. The results indicated a significant relationship, $\mathrm{F}(15,393)=1.95, \mathrm{p}=.018$.

\section{Discussion}

Pintrich and de Groot (1990) established that performance relies on the interplay of variables, which was observed in this study. No single variable can be used as a predictor of optimal motivation or academic success; instead, there are many. Self-efficacy of distance-learning students has been determined to significantly predict student satisfaction (Holder, 2007; Liaw, 2008) and is also correlated with online student performance (Richardson, 2007; Spahr, 2015). We identified that self-efficacy of online students not only correlated positively with final grade, but also with endogenous instrumentality, connectedness, and knowledge-building scales. It is interesting, but not surprising, to note that extrinsic instrumentality negatively correlated with all study variables, including final course grade. As this study is one of the first to evaluate performance using the new extrinsic instrumentality scale (Puruhito, 2017), our findings offer a new understanding of motivation strategies and achievement outcome specifically for online students.

RQ1 -Gender. Richardson (2007) considered differences between gender and found selfefficacy to be significantly higher for male distance-learning students. While our study did not replicate this result, a MANOVA analysis identified significant variation between genders on other study variables. Knowledge building, connectedness and endogenous instrumentality, and exogenous instrumentality scales were all significantly higher among female students compared to their male counterparts. Males, on the other hand, were found to have significantly higher extrinsic instrumentality. Performance, as determined by final course grade, was comparable between genders. It is worth noting, however, that the groups in our study were not equal in size. This sample was only $16.8 \%$ male.

RQ2a - Major. Not all students enrolled in distance-learning family science courses are family science majors. As such, it is beneficial to consider how major/non-major status and potential differences in perceived content relevance influence motivation. We anticipated that concepts and material presented would be viewed as having greater endogenous instrumentality to students majoring in a field related to the course content; in this study that included family and human development (FHD) majors. We purported that FHD majors would show greater knowledge-building and connectedness scores. Results indicated that majors had significantly higher self-efficacy, knowledge-building and connectedness orientations, as well as higher endogenous and exogenous instrumentality. Non-majors, in contrast, had significantly higher extrinsic instrumentality even though performance was found to be uniform. This is consistent with previous research on motivation. Non-majors have a harder time finding value in the content they learn in non-major courses (Shell \& Husman, 2001). This study shows that this holds true for online students as well. 
RQ2b -Final Course Grade. Optimizing graduation rates is a core concern for most universities. In order to measure progress on learning goals, we assign grades. It is no wonder that students become so grade focused since it is how they are evaluated. The courses that students reported on for this study all had high success rates and, as such, our data were positively skewed with more than half of all students receiving an A. Only 17 (4.2\%) students who participated in the study did not pass their class. While no significant difference in final course grades between majors and non-majors was found, interesting findings related to final course grades nonetheless emerged. Students completed the survey a little after the midpoint of the course, and there was a strong correlation in extrinsic instrumentality reported at that point in time and final course grade earned at the end of week 7 . This indicates that extrinsic instrumentality can be used to predict student success (or lack thereof), but it is also an opportunity for instructors to intervene. If we are mindful of the messages that we transmit to students about what is important (e.g. learning the content and how it can be used in the future, not the grade) and how information is useful for their everyday lives and futures, then perhaps we can adjust students' orientations and increase their success. Future research could provide a greater understanding of ways educators can meet the needs of a growing distance-learning population by further investigating these relationships and exploring interventions to help increase students' endogenous instrumentality and decrease their extrinsic instrumentality.

\section{Conclusion}

When students fail to see how they can utilize the information they are learning for their future beyond simply receiving a passing grade that allows them to move one step closer to graduation, learning and performance suffer. This is true for both campus-based and online students. They are less likely to be successful in a course when they focus on the exogenous instrumentality of the course, as indicated in this study. Our study reinforced previous findings of a positive correlation between self-efficacy and student performance found in campus-based students (Chemers et al., 2001; Honicke \& Broadbent, 2016; Zajacova et al., 2005;). Shell and colleagues (2005) explored perceptions of value among traditional students. We desired to understand if distance-learning students would also have greater knowledge-building motivation when course content related to future goals. We found that distance-learning students enrolled in a course specific to their major showed greater endogenous instrumentality, knowledge building, connectedness to their future, and self-efficacy. These findings align with the Shell et al. (2005) study focused on traditional campus students. While it is certainly beneficial to understand what factors predict success, it is equally essential that we understand motivational beliefs that undermine performance and knowledge acquisition. Our study is unique and adds to the literature, in that we observed a negative correlation between extrinsic instrumentality and student performance. Correlations we observed between extrinsic instrumentality and learning outcomes reinforce the validity of the newly created measure. As our study focused solely on distance learning students, we deduce that self-efficacy, use of knowledge-building skills, and amount of extrinsic instrumentality are all predictors of success that can be generalized among postsecondary students enrolled in various contexts.

Furthermore, this research aids in our understanding of factors that instructors need to be mindful of while teaching. While grades are important for many reasons, reinforcing a grade rather than learning orientation can have detrimental outcomes for students. It is important to make sure that we aid student learning by embedding opportunities for students to connect what they are learning with its value for their future, even if they are not majoring in a related field. 
Going the Distance: Online Course Performance and Motivation of Distance Learning Students

\section{References}

Allen, I. E., \& Seaman, J. (2017). Digital learning compass: Distance education enrollment report 2017. Retrieved from https://onlinelearningsurvey.com/reports/digtiallearningcompassenrollment2017.pdf

Bandura, A. (1997). Self-Efficacy: The exercise of control. New York, NY: W.H Freeman and Company.

Bembenutty, H. (2009). Academic delay of gratification, self-regulation of learning, gender differences, and expectancy-value. Personality and Individual Differences, 46(3), 347352 .

Bong, M. (2001). Role of self-efficacy and task-value in predicting college students' course performance and future enrollment intentions. Contemporary Educational Psychology, 26(4), 553-570.

Boston, W. \& Ice, P. (2010). Comprehensive Assessment of Student Retention in Online Learning Environments. In J. Sanchez \& K. Zhang (Eds.), Proceedings of E-Learn 2010--World Conference on E-Learning in Corporate, Government, Healthcare, and Higher Education (pp. 1593-1599). Orlando, Florida, USA: Association for the Advancement of Computing in Education (AACE). Retrieved July 19, 2018 from https://www.learntechlib.org/primary/p/35779/.

Chemers, M. M., Hu, L. T., \& Garcia, B. F. (2001). Academic self-efficacy and first year college student performance and adjustment. Journal of Educational Psychology, 93(1), 55-64.

Craig, A. J., \& Ward, C. V. L.(2009) Retention of community college students: Related student and institutional characteristics. Journal of College Student Retention, 9(4), 505-517.

Eccles, J. S., \& Wigfield, A. (1995). In the mind of the actor: The structure of adolescents' achievement task values and expectancy-related beliefs. Personality and Social Psychology Bulletin, 21, 215-225.

Hilpert, J. C., Husman, J., Stump, G. S., Kim, W., Chung, W.-T., \& Duggan, M. A. (2012). Examining students' future time perspective: Pathways to knowledge building. Japanese Psychological Research, 54(3), 229-240.

Holder, B. (2007). An investigation of hope, academics, environment, and motivation as predictors of persistence in higher education online programs. The Internet and Higher Education, 10(4), 245-260.

Honicke, T., \& Broadbent, J. (2016). The influence of academic self-efficacy on academic performance: A systematic review. Educational Research Review, 17, 63-84.

Husman, J., Derryberry, W. P., Crowson, H. M., \& Lomax, R. (2004). Instrumentality, task value and intrinsic motivation: Making sense of their independent interdependence. Contemporary Educational Psychology, 29, 63-76.

Husman, J., \& Lens, W. (1999). The role of the future in student motivation. Educational Psychologist, 34(2), 113-125. 
Going the Distance: Online Course Performance and Motivation of Distance Learning Students

Kim, W. (2016). Endogenous and Exogenous Instrumentality on Student Motivation and Achievement. (Doctoral Dissertation). Retrieved from https://repository.asu.edu/items/40307.

Lang, F. R., \& Carstensen, L. L. (2002). Time counts: Future time perspective, goals, and social relationships. Psychology \& Aging, 17(1), 125-139.

Lens, W. (2002). How to combine intrinsic task-motivation with the motivational effects of the instrumentality of present tasks for future goals. In J. K. A. Efklides, Trends and Prospects in Motivation Research. Netherlands: Springer.

Liaw, S. S. (2008). Investigating students' perceived satisfaction, behavioral intention, and effectiveness of e-learning: A case study of the Blackboard system. Computers \& Education, 51(2), 864-873.

Malka, A., \& Covington, M. V. (2005). Perceiving school performance as instrumental to future goal attainment: Effects on graded performance. Contemporary Educational Psychology, 30(1), 60-80.

Miller, R. B., DeBacker, T. K., \& Greene, B. A. (1999). Perceived instrumentality and academics: The link to task valuing. Journal of Instructional Psychology, 26(4), 250-260.

Multon, K. D., Brown, S. D., \& Lent, R. W. (1991). Relation of self-efficacy beliefs to academic outcomes: A meta-analytic investigation. Journal of Counseling Psychology, 38, 30-38.

National Center for Education Statistics. (2014). Enrollment in distance education courses, by state: Fall 2012. Retrieved from https://nces.ed.gov/pubs2014/2014023.pdf .

National Center for Education Statistics. (2018). Digest of Education Statistics, 2016. Retrieved from https://nces.ed.gov/fastfacts/display.asp?id=80 .

Pintrich, P. R., \& de Groot, E. V. (1990). Motivational and self-regulated learning components of classroom academic performance. Journal of Educational Psychology, 82(1), 33-40.

Puruhito, K. K. (2017). Connecting to the future: a revised measure of exogenous perceptions of instrumentality (Doctoral Dissertation). Retrieved from: https://repository.asu.edu/attachments/186650/content/Puruhito asu 0010E 17111.pdf

Richardson, J. T. (2007). Motives, attitudes and approaches to studying in distance education. Higher education, 54(3), 385-416.

Rovai, A. P. (2003). In search of higher persistence rates in distance education online programs. The Internet and Higher Education, 6(1), 1-16.

Rush, K. (2013). A Quantitative Evaluation of Gender, Nationality, and Generational/Age Influence on Academic Motivation (Doctoral dissertation). Retrieved from ProQuest LLC. (Accession No. 3574680).

Shell, D. F., Colvin, C. \& Bruning, R.H. (1995). Self-Efficacy, attribution, and outcome expectancy mechanisms in reading and writing achievement: grade-level and achievement-level differences. Journal of Educational Psychology, 87, 386-398.

Shell, D.F., Murphy, C.C., \& Bruning, R. H. (1989). Self-efficacy and outcome expectancy mechanisms in reading and writing achievement. Journal of Educational Psychology, $81,91-100$. 
Shell, D. F., \& Husman, J. (2001). The multivariate dimensionality of personal control and future time perspective beliefs in achievement and self-regulation. Contemporary Educational Psychology, 26(4), 481-506.

Shell, D.F., \& Husman, J. (2008). Control, motivation, affect, and strategic self-regulation in the college classroom: A multidimensional phenomenon. Journal of Educational Psychology, 200(2), 443-459. DOI: 10.1037/0022-0663.100.2.443 .

Shell, D. F., Husman, J., Turner, J. E., Cliffel, D. M., Nath, I., \& Sweany, N. (2005). The impact of computer supported collaborative learning communities on high school students' knowledge building, strategic learning, and perceptions of the classroom. Journal of Educational Computing Research, 33(3), 343-360.

Shell, D. F., \& Soh, L. K. (2013). Profiles of motivated self-regulation in college computer science courses: Differences in major versus required non-major courses. Journal of Science Education and Technology, 22, 899-913.

Simons, J., Dewitte, S., \& Lens, W. (2004). The role of different types of instrumentality in motivation, study strategies, and performance: Know why you learn, so you'll know what you learn! British Journal of Educational Psychology, 74(3), 343-360.

Simpson, O. (2013). Student retention in distance education: Are we failing our students? Open Learning: The Journal of Open and Distance Learning, 28(2), 105-119.

Smith, B. (2010). E-learning technologies: A comparative study of adult learners enrolled on blended and online campuses engaging in a virtual classroom (Doctoral dissertation). Retrieved from ProQuest Dissertations and Theses Database.

Spahr, M. L. (2015). Gender, Instructional Method, and Graduate Social Science Students' Motivation and Learning Strategies (Unpublished doctoral dissertation). Walden University, Minneapolis, MN.

Wigfield, A., \& Eccles, J. S. (1992). The development of achievement task values: A theoretical analysis. Developmental Review, 265-310.

Wigfield, A., \& Eccles, J. S. (2002). The development of competence beliefs, expectancies for success, and achievement values from childhood through adolescence. In A. Wigfield, \& J. S. Eccles (Eds.), Development of Achievement Motivation. San Diego: Academic Press.

Willging, P. A., \& Johnson, S. D. (2009). Factors that influence students' decision to drop out of online courses. Journal of Asynchronous Learning Networks, 13(3), 115-127.

Yoo, S., \& Huang, W. (2013). Engaging online adult learners in higher education: Motivational factors impacted by gender, age, and prior experiences. The Journal of Continuing Higher Education, 61(3), 151-164.

Zajacova, A., Lynch, S. M., \& Espenshade, T. J. (2005). Self-efficacy, stress, and academic success in college. Research in Higher Education, 46(6), 677-706.

Zimbardo, P. G., \& Boyd, J. N. (1999). Putting time in perspective: A valid, reliable individualdifferences metric. Journal of Personality and Social Psychology, 77(6), 1271-1288.

Zimmerman, B. J., \& Bandura, A. (1994). Impact of self-regulatory influences on writing course attainment. American Educational Research Journal, 31, 845-862. 